\title{
Harmonious development and dynamic correlation analysis of new energy industry agglomeration innovative human capital and green economic growth
}

\author{
Yubo Wang, Aohan $\mathrm{Li}^{*}$, and Shiyun Cheng \\ School of Economics and Management, Hubei Univ. of tech., Wuhan 430068, China
}

\begin{abstract}
By selecting the data from 2004 to 2016, this paper studies the coupling and coordinated development of new energy industry agglomeration, innovative human capital and green economic growth in China. The results show the characteristics of "high coupling and low coordination". At the same time, the coordination level shows a step-like distribution from the southeast coastal areas to the southwest and northwest regions. Through the establishment of PVAR model, it is found that the energy industry agglomeration and economic green development have a circular driving force, while the innovative human capital has a negative effect. The regional heterogeneity mainly exists in the central and western regions.
\end{abstract}

\section{Introduction}

As an emerging strategic industry, the new energy industry not only has the potential driving force for economic growth, but also has the characteristics of coordinated development with regional resources and environment, which conforms to the concept of "green growth" of current sustainable economic development. At present, the new energy industry has emerged the characteristics of industrial clusters, but the market is not mature, lack of core scientific and technological support and other difficulties. It is not clear whether the production organization framework of industrial clusters and the intellectual support of human capital can effectively interact with the green development of regional economy. Therefore, the agglomeration of new energy industry, innovative human capital and green economic growth are taken as three subsystems within a system to explore whether there is an endogenous correlation that promotes and facilitates each other. It provides reference for the study of agglomeration development of new energy industry.

\section{Literature review and coupling analysis}

There are many literatures studying the coupling and coordinated development of industrial development, human capital and regional economic growth. Shuang Qiu [1] found in his research that the coupling and coordinated development degree between the steel industry, ecological environment and regional economic system in Panzhihua City has been continuously strengthened. Yuzhu Li [2] found that from 2009 to 2018, the coupling degree between economic development and the supply of high-skilled talents increased slowly, while the coordinated development degree increased rapidly, and the mutual contribution degree between them was not equal. Di Zhou [3] found that the coupling degree between human capital and economic growth in the five major urban agglomerations increased slowly and showed a polarization phenomenon, and there was an obvious dynamic disharmony between them. The coupling mechanism among the industrial agglomeration, human capital and economic growth is further analyzed by referring to scholars such as Qintang Wu [4] (Figure $1)$ :

Coupling of industrial cluster and regional economic growth mainly reflected in: firstly, the industrial concentration is bound to cause the spatial concentration of population in agglomeration area, further it will creat the demand of basic industries in various fields, such as living consumption, housing, energy, transportation. The continuous development of various industry will drive the expansion of the agglomeration area and the improvement of the improvement of the infrastructure, and lead to the positive interaction between the industry and the agglomeration area. Secondly, the unique relevance between industries will cause the continuous extension of a regional industrial chain. In order to reduce costs and seek economies of scale, the industries that compete with and complement each other in a certain field tend to concentrate in spatial distribution, and then form a complete industrial system chain. This is an important basis for regional economic growth. Thirdly, innate regional advantages such as location characteristics and resource endowment under industrial agglomeration are important factors for the formation of characteristic industrial clusters. The competitive

\footnotetext{
*Corresponding author: 291703307@qq.com
} 
advantages of these characteristic industrial clusters are difficult to be imitated, especially for the new energy industry. Therefore, regional resource conditions become the primary condition for industrial development, which has a strong driving force for regional economic growth.

The coupling between industrial agglomeration and innovative talents is shown in the following aspects: at first, within an industrial cluster, it will form a regional information network due to its close geographical location. The effective flow of market information and technical information will effectively reduce the cost of accurate matching between positions and professionals. At the same time, the exchange of technical information has also become an important driving force for the gathering of innovative talents, and professionals will also provide strong support for regional industrial upgrading. Second, the fierce competition within industrial clusters intensifies the demand for senior talents, and the cluster mechanism can provide innovators with resources, such as talents, funds, equipment and tools, which can play a more technical spillover effect in the main motivation, environment, organization and other aspects of innovation.

Coupling of creative talents and economic growth. Innovation is the driving force of productivity development. When innovative talents are matched with economic development, innovative talents promote technological innovation and transformation of scientific and technological achievements through intellectual achievements, and provide power for sustainable economic development. At the same time, investment in talent training cannot be separated from economic support and material guarantee, and economic growth will also react on the training and supply of innovative talents.

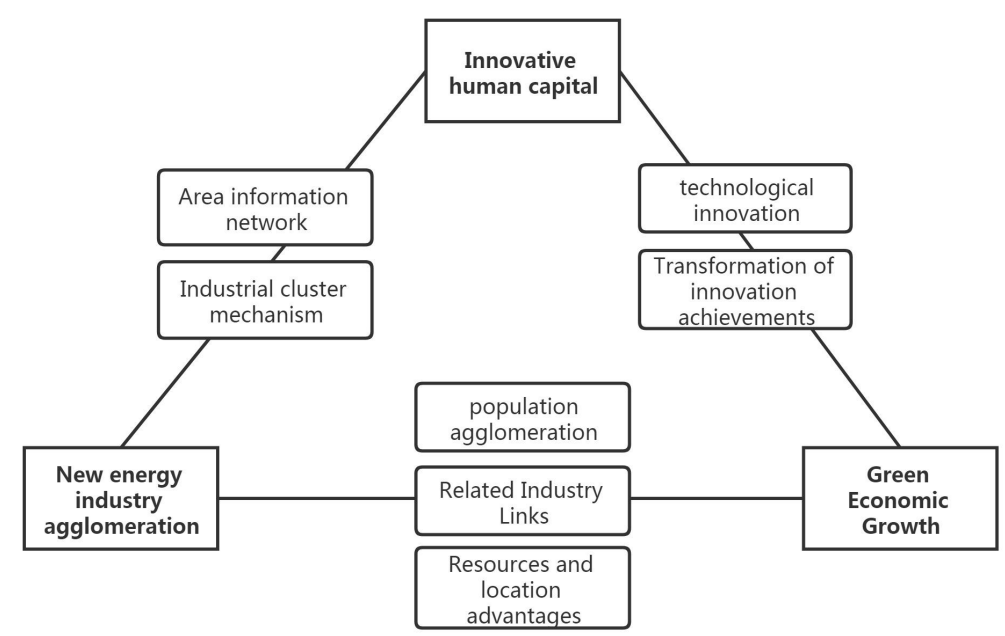

Figure 1. Coupling relation diagram of new energy industrial agglomeration, innovative human capital and green economic growth

\section{Materials and Methods}

\subsection{Methods}

\subsubsection{Comprehensive evaluation index based on entropy weight method}

Because different indexes have different dimensions and meanings, the original data need to be dimensionless first. In this paper, the range method is used to standardize the data. Secondly, the index weight is determined by calculating the relevant information entropy, and finally the index evaluation score can be calculated.

Positive indicators

$X_{i j}^{\prime}=\frac{X_{i j}-\min \left\{X_{j}\right\}}{\max \left\{X_{j}\right\}-\min \left\{X_{j}\right\}}$

Negative indicators

$$
\begin{aligned}
& X_{i j}^{\prime}=\frac{\max \left\{X_{i j}\right\}-X_{j}}{\max \left\{X_{j}\right\}-\min \left\{X_{j}\right\}} \\
& Y_{\mathrm{ij}}=\frac{X_{i j}^{\prime}}{\sum_{\mathrm{i}=1}^{\mathrm{m}} X_{\mathrm{ij}}^{\vee}} \\
& d_{j}=1-\left[\left(-k \sum_{i=1}^{m}\left(Y_{i j} \times \ln Y_{i j}\right)\right]\right. \\
& W_{i}=d_{j} / \sum_{j=1}^{n} d_{j} \\
& S_{i j}=W_{i} \times X_{i j}
\end{aligned}
$$

In the type: $X_{i j} X_{i j}$ represent the original and standardized values, $\min \left\{X_{j}\right\}$ and $\max \left\{X_{j}\right\}$ are the minimum and maximum values of the evaluation index in all the years, $Y_{i j}$ represents the proportion of the evaluation index in the year, $d_{j}$ represents the redundancy of information entropy of the evaluation index. $\mathrm{k}=1 / \mathrm{ln}(\mathrm{m})$, here $\mathrm{m}$ is the number of evaluation years, " $n$ " is the number of indicators, $W_{i}$ is the weight of indicators, and 
$S_{i j}$ is the single indicator evaluation score.

\subsubsection{Coupling coordinate degree model}

\section{(1) Coupling degree model}

Referring to the capacity coupling coefficient model in physics that can measure the dynamic correlation between two or more systems, the formula is shown in (6). The degree of coupling mainly measures the degree of interaction between various systems, while the degree of coupling coordination mainly reflects the degree of consistency of coordination between various systems. In the formula, $\mathrm{C}$ represents the coupling degree of new energy industrial agglomeration, innovative human capital and green economic growth, and $C \in[0,1]$. The closer $C$ is to 1 , the better the coupling degree is.

$$
C=\left\{\frac{S_{1} \times S_{2} \times S_{3}}{\left.\left[\left(S_{1}+S_{2}+S_{3}\right) / 3\right)\right]^{3}}\right\}^{1 / 3}
$$

\section{(2) Coupling coordinate degree model}

In order to obtain the development level of coupling coordination among the three systems more accurately, the coupling coordination model (7) is introduced. $D$ is the coordination degree. The greater the value of $D$ is, the better the benign coupling and coordinated development among the three systems are. $T$ is the comprehensive evaluation index of the three systems, which can reflect the overall level of the three systems. $\alpha$, $\beta$ and $\delta$ are the undetermined coefficients of the agglomeration of new energy industry, innovative human capital and green economic growth respectively, and they represent the degree of contribution to economic and social development respectively. Considering that the innovation level of new energy industry and human capital is more dependent on regional economic strength, the following values are obtained $\alpha=0.3 \beta=0.3 \delta=0.4$.

$$
\begin{aligned}
& D=\sqrt{C \times T} \\
& T=\alpha S_{1}+\beta S_{2}+\delta S_{3}
\end{aligned}
$$

\section{(3) Panel vector autoregressive model}

In this paper, the panel vector autoregressive model is adopted to study the dynamic relationship between new energy industry agglomeration, innovative human capital and green economic growth as endogenous variables, and a PVAR model including fixed effect and period effect is constructed to study the dynamic relationship between them. On the one hand, impulse response analysis is carried out to study how the influence of disturbance term spreads to various variables. The model is constructed as follows, and $Y_{i t}=\left\{\operatorname{lnperggd} p_{i t}, q_{i t}, h c i_{i t}\right\}$

$$
\mathrm{y}_{i t}=\alpha_{0}+\sum_{j=1}^{n} \beta_{j} y_{t-j}+f_{i}+d_{i}+\varepsilon_{i t}
$$

In the above formula, $y_{i t}$ represents the vector composed of endogenous variables, which are respectively new energy industrial agglomeration, innovative human capital and green economic growth, the subscript $i$ represents 30 provinces in China, $t$ for the year, $j$ represents variable lag order, $y_{t-j}$ represents all of the endogenous variable, $\alpha_{0}$ represents the intercept, $\beta_{j}$ represents the regression coefficient matrix, $f_{i}$ and $d_{i}$ represents fixed effect and time effect, $\varepsilon_{i t}$ represents random disturbance. The program used in this paper comes from the PVAR2 program improved by Yujun Lian and Ryan Docker, and the software used is Stata15.

\subsection{Data source and description}

\subsubsection{New Energy Industry Cluster (lq)}

Referring to the method proposed by Shizhong Li and Liwei Guo [5], only production and manufacturing links in the new energy industry chain are selected, and the sales value of general equipment manufacturing industry and electrical machinery and equipment manufacturing industry is used to represent the output value of the new energy industry. Referring to the methods of Chen $\mathrm{Lu}, \mathrm{Li}$ Jun [6-7], the method of location quotient selection can be used to measure the degree of industrial agglomeration. The calculation formula is as follows:

$l q=\frac{E_{i j} / E_{i}}{E_{k j} / E_{k}}$

$E_{i j}$ refers to the output value of industry $j$ in region $I$, $E_{i}$ refers to the total output value of region $I, E_{k j}$ refers to the total output value of industry $j$ in country, and $E_{k}$ refers to the total output value of country.

\subsubsection{Human Capital Innovation (hci)}

When most scholars at home and abroad calculate the stock of innovative human capital, they all consider the relevant indicators of undergraduate degree and above, and determine the amount of innovative human capital through the number of labor and the average length of education. This method takes into account more problems of different educational levels and cannot effectively reflect the overall level of human capital innovation in a region. Drawing on the research of Yuyan Wang [8], the proportion of R D personnel and industry practitioners is used to reflect the level of human capital innovation in China. At the same time, considering the uniformity and pertinence of the data index, the ratio of R\&D personnel to the total number of employees in industrial enterprises above designated size is selected to measure the level of human capital innovation. The number of industry employees in 2012 and 2013 was calculated by other indicators.

\subsubsection{Green Economic Growth(Inperggdp)}

For the measurement of green economic growth, referring the method of Feng Wang. The cost of energy consumption and environmental pollution is taken into account on the basis of traditional output [9]. As for energy consumption, it is measured by the consumption 
value of coal, crude oil, natural gas and other fossil fuels, among which the international units are selected as the coal price in Northwest Europe, spot Brent crude oil spot price and Henley + natural gas price in the United States. In terms of environmental pollution, the method and price data in the Green National Economic Accounting Report of 2004 are referred to to calculate from three aspects: waste water, waste gas and industrial solid waste. (Calculation formula: loss value $\approx$ unit price * consumption / emissions). The accounting formula is as follows:

$$
G G D P_{\mathrm{i} t}=G D P_{\mathrm{it}}-\sum_{\mathrm{k}=1}^{3} C_{\mathrm{itk}}-\sum_{j=1}^{3} E_{i \mathrm{ij}}
$$

In the above formula, GGDP represents green GDP, $i$ represents each province, $t$ represents year, $k$ represents type of energy consumption, and $j$ represents type of environmental cost, $\sum_{\mathrm{k}=1}^{3} \mathrm{C}_{i t k}$ represents the sum of energy consumption, $\sum_{\mathrm{j}=1}^{3} E_{i t j}$ represents the cumulative cost of environmental pollution.

Considering the unbalanced regional economic development as well as the differences in population size, only by regional GDP is difficult to measure the actual condition of economic development, according to the end of the regional resident population to calculate per capita $G G D P$ to measure, at the same time to reduce variables influence to the exponential heteroscedastic processing, as lnperggdp, as indicators of green growth.

\section{Results and discussion}

\subsection{Analysis of coupling coordination results}

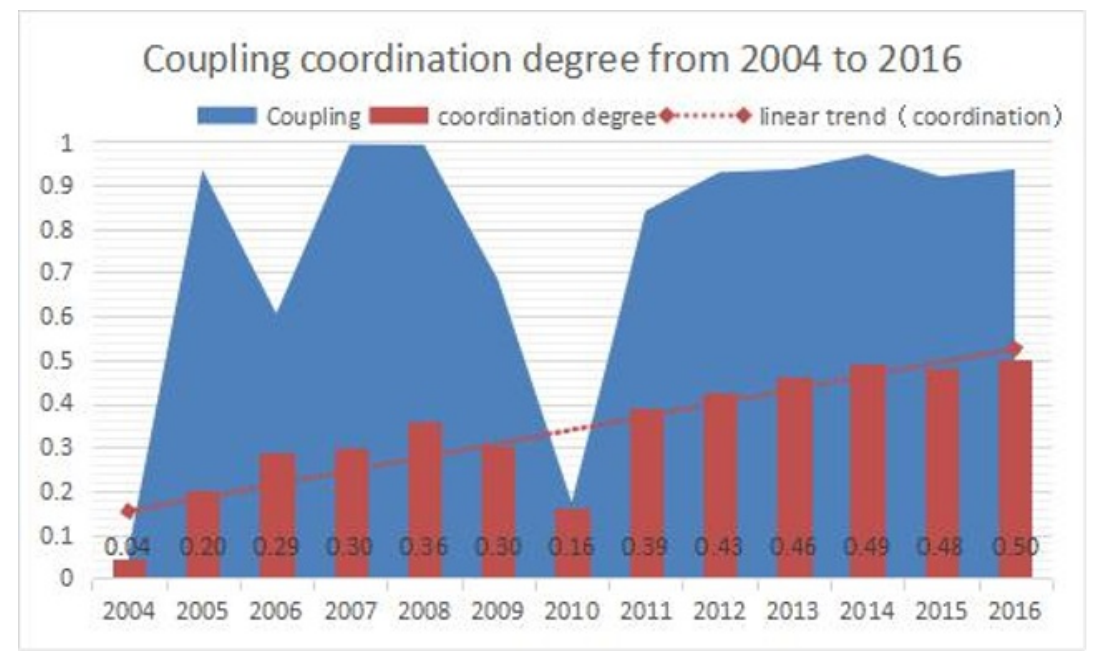

Figure 2. New energy industrial agglomeration, innovative human capital and green economic growth coupling coordination degree

As can be seen from the above table 2, as a whole there is a high coupling between new energy industrial agglomeration, innovative human capital and green economic growth, but the fluctuation is large in the first six years, it indicates that the interaction of the three systems in the early stage is not stable, until 2011, the three systems are in a stable and high coupling state. From the perspective of coordination degree, the coordinated development among the three is in the phase of maladjustment decline, and gradually develops from severe maladjustment to mild maladjustment during the ten years. This indicates that the positive effect of mutual promotion and mutual promotion among the them gradually strengthen, and they enter the phase of forced coordination in 2016. From the perspective of time series, the coupling degree and coordination degree of the three systems show a linear trend of growth, indicating that the interaction between the three systems is also continuously enhanced.

From the point of view of coupling degree or coordination degree, the year of 2010 is at a key node, which may be due to the fact that industrial agglomeration and talent aggregation in the early stage are in a run-in development time for the sustainable economic development. It shows periodic fluctuations, and it is in a stable development state until 2016. Further, from Table 3, we can see that the coordination degree has not changed in most of the six years, and the coordinated development of more than a dozen provinces has been significantly improved. For the eastern coastal areas such as Shanghai, Jiangsu, Zhejiang and Guangdong, the coordinated development speed and degree are relatively good, while the development of the central inland areas is relatively stable. Qinghai, Ningxia and Mongolia in the northwest and Yunnan and Hainan in the south have poor coordinated development. It can also be seen that the coordinated development of the three areas presents a ladder distribution, which shows that the southeast coastal areas are better, the central inland areas are relatively stable, and the northwest and southwest areas are less developed. 
Table 1. The changes in the degree of coordinated development between regions from 2010 to 2016

\begin{tabular}{lcl}
\hline & Variation in the degree of coordination & \multicolumn{1}{c}{ region } \\
\hline \multirow{2}{*}{$\begin{array}{l}\text { Remain } \\
\text { unchanged }\end{array}$} & in serious disorders & Qinghai, Guizhou, Yunnan, Shanxi, Ningxia, Inner Mongolia \\
& in moderate disorders & Jiangxi, Fujian, Hebei \\
& in a mild disorder & Hubei, Hunan, Chongqing, Shandong, Anhui \\
narrowly coordination & Shanghai, Jiangsu \\
& from serious disorder to moderate disorders & Guangxi, Xinjiang, Jilin, Gansu \\
from moderate to mild disorder & Heilongjiang, Henan, Sichuan, Liaoning, Shaanxi \\
& from mild disorder to barely coordinated & Guangdong, Beijing \\
& from moderate to severe disorder & Hainan \\
\hline
\end{tabular}

\subsection{Dynamic correlation analysis}

This paper further analyzes the development status of high coupling and low coordination between new energy industrial agglomeration, innovative human capital and green economic development as well as the regional development differences. And it explores the dynamic connection among the three and the reasons for regional differences from the perspective of endogenicity by constructing the PVAR model.

\subsubsection{Unit root test}

Table 2. Unit root test

\begin{tabular}{ccccc}
\hline \multirow{2}{*}{ variable } & \multicolumn{2}{c}{ LLC test } & \multicolumn{2}{c}{ Fisher test } \\
& Statistic & p-value & Statistic & p-value \\
\hline lq & -1.673 & 0.0472 & 142.2924 & 0.000 \\
lnperggdp & -3.8445 & 0.0001 & 175.4481 & 0.000 \\
ihc & -5.9975 & 0.000 & 194.9716 & 0.000 \\
\hline
\end{tabular}

Before data processing, it is necessary to test the stationaryness of the data. As can be seen from Table 2, according to the results of LLC test and Fisher test, the data is stable and can be directly analyzed empirically. Further, in order to determine the optimal lag order, the PVAR2 installation package program of Yujun Lian was used to determine the optimal lag order as 4 orders by $\mathrm{AIC}, \mathrm{BIC}$ and HQIC criteria. The co-integration test is further carried out, and the null hypothesis is: there is no co-integration relationship between variables through three test methods, Kao, Pedroni and Westerlund. The results in Table 3 show that the null hypothesis is rejected at the level of $1 \%$ for tests with at least one statistic in each test method, that is, there was co-integration relationship between variables in at least part of the region.

Table 3. Co-integration test results

\begin{tabular}{cccc}
\hline Test & statistic & Statistic value & P-value \\
\hline \multirow{4}{*}{ Kao Test } & Modified Dickey-Fuller t & 5.1454 & 0 \\
& Dickey-Fuller t & 6.2507 & 0 \\
& Augmented Dickey-Fuller t & 7.406 & 0 \\
& Unadjusted modified Dickey & 1.5509 & 0.0605 \\
& Unadjusted Dickey-Fuller t & -0.0677 & 0.473 \\
\multirow{3}{*}{ Pedroni Test } & Modified Phillips-Perron t & 4.7941 & 0 \\
& Phillips-Perron t & -2.0629 & 0.0196 \\
Westerlund Test & Augmented Dickey-Fuller t & -0.7297 & 0.2328 \\
\hline
\end{tabular}

\subsubsection{Impulse response analysis}

Impulse response function can analyze the influence of variables under the impact of themselves and other variables as well as the changes in each stage. The impulse response graphs in the figure below are all obtained by root Monte-Carlo simulation for 200 times. 
The dotted line represents the upper and lower bounds at the $95 \%$ confidence level. The horizontal axis in the figure represents the number of lag periods (unit: year) of impact. The vertical axis represents the response of the explained variable to the impact of each explanatory variable (i.e., impulse value).

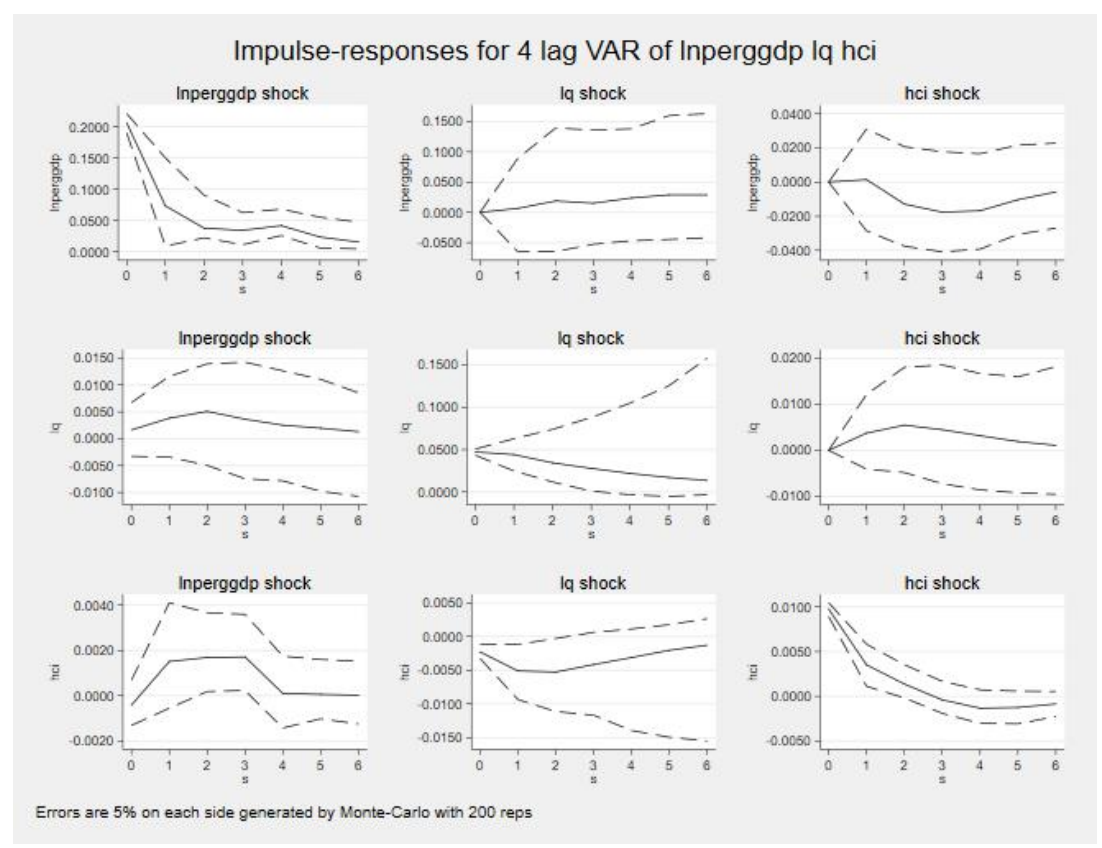

Figure 3. Full sample impulse response diagram

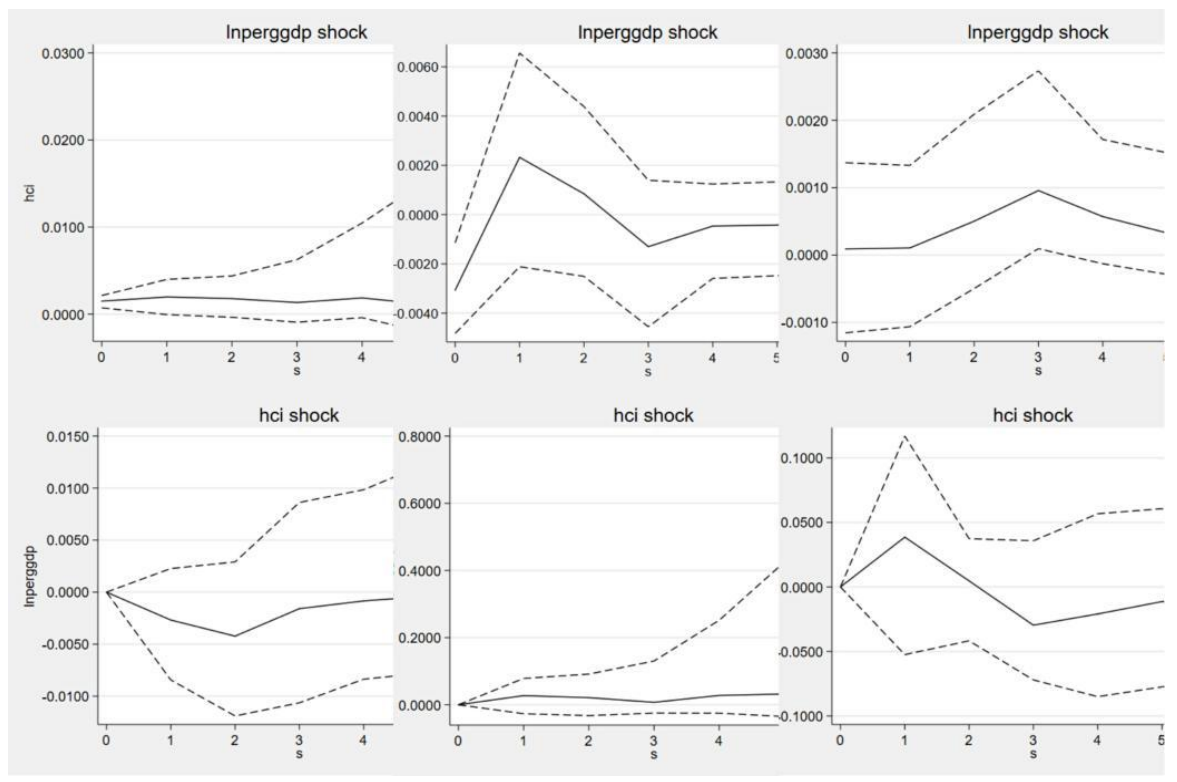

Figure 4. Pulse response diagram of LNPERGGDP and HCI in the eastern and western regions

As can be seen from the Fig.3, there is a positive impact effect between new energy industry agglomeration and green economic growth, and the driving force is relatively stable. The interaction between the agglomeration level of new energy industry and innovative human capital is opposite, which indicates that the agglomeration of new energy industry promotes the accumulation of human capital to some extent, but the human capital to some extent restricts the development of new energy industry. The opposite force between the two is relatively stable. Innovative human capital has a positive impact on the growth of green economy, which tends to zero in the fourth period, indicating that this positive impact exists in the short term, while green economic growth has a negative impact on innovative human capital in the first period, which is also consistent with the results in the GMM test.

According to the impulse response analysis of national sample size, new energy industry agglomeration, innovative human capital and green economic development all have positive or negative impact, which also indicates that there is a significant interaction between the three, thus showing a high coupling feature. Impact between the two at the same time the influence degree of the effect is mostly at around $1 \%$, and the 
impact of the reverse inhibitor (human capital, innovation ability cannot be converted to the new energy industry cluster advantage, economic conditions to ensure the material has yet to provide talent), which may explain the reasons of lower degree of coordinated development of the overall

For further analysis of the new energy and industrial concentration, innovative the interaction between human capital and economic growth of green effects are influenced by the regional differences and then presents the coordination degree of gradually decreasing from the east to the west of the region characteristic, national sample size can be divided into features three parts analyze each line (impulse response figure features region, respectively).

The eastern part of the innovative human capital has a short-term positive effect on green economic growth, and green economic growth overall for negative impact to the innovative human capital. This is consistent with the sample analysis, it shows that the innovation of the current our country high-end talent value has not been effectively play and unable to long-term stability of intellectual achievements into economic value. Economic development has not promoted the concentration of talent. The impact of innovative human capital on the growth of green economy in the central region is negative first, then positive and then negative, which indicates that the value advantage of talents has not been effectively played or even will inhibit the regional economic development, and the economic growth in the central region has no significant impact on talent agglomeration. The impact of green economic growth on innovative human capital in western China is positive first and then negative, indicating the lack of long-term and stable economic support for talent accumulation.

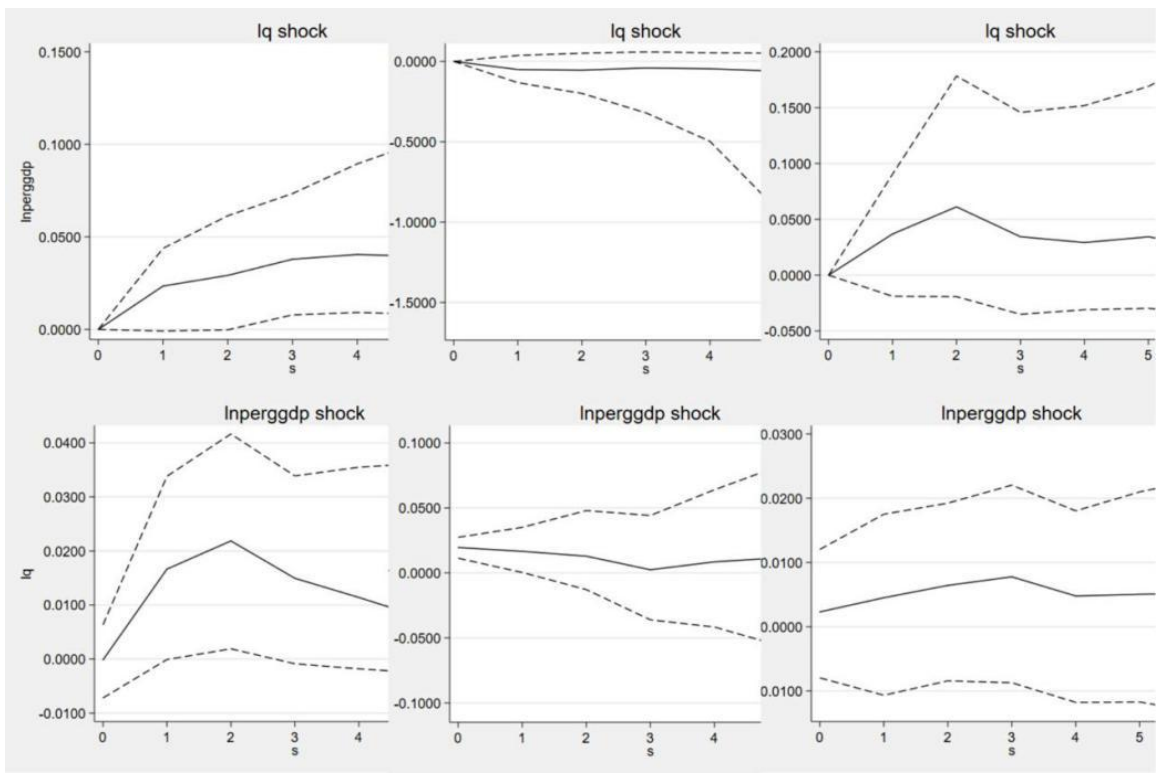

Figure 5. Pulse response diagram of LNPERGGDP and LQ in the eastern and western regions

The interaction between the new energy industry agglomeration and the green economic growth in the eastern and western regions presents an obvious positive promoting effect, while the green economic growth in the central region is basically consistent with the zero scale line, and there is no obvious negative correlation between the new energy industry agglomeration. The interaction between green economic growth and new energy industry agglomeration in the eastern, central and western regions is basically consistent with the analysis of the national sample, and there is no significant regional heterogeneity. This indicates that the development momentum of the new energy industry is good, which plays a positive role in promoting the green development of the region. Meanwhile, it also reflects that the cultivation and support policies for the new energy industry have achieved certain effects, providing effective economic support for the development of the new energy industry.
East innovative interaction between human capital and the new energy industry agglomeration in sample analysis conclusion is consistent, and it shows that the new energy industry cluster to promote local high-end talent gathered, but inhibit the development of new energy industry innovative talents. This may be due to the policy under the support of talents converging no support for the new energy industry development to provide intellectual property. Lack of professional core technology, imperfect supporting infrastructure, personnel security is not implemented and other reasons. There is no correlation between human capital and economic growth in the central region, while the human capital in the western region has a negative impact on the new energy industry, which may be because relying on the resource endowment advantage in the western region, the accumulation of long-term high-end human capital will promote the development of the local new energy industry. 


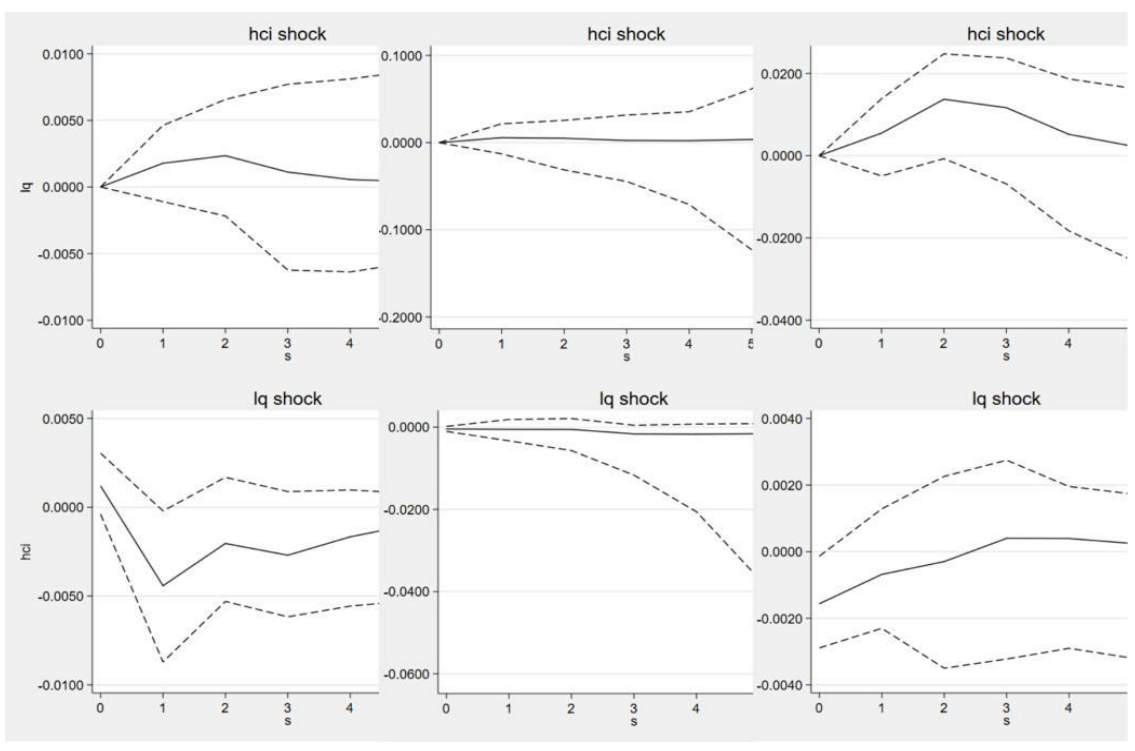

Figure 6. Impulse response diagram of HCI and LQ in eastern, central and western regions

Based on the above regional analysis results: Contrast samples from different area, the eastern part of new energy and industrial concentration, innovative the interaction between human capital and economic development of green analysis results are basically identical with the sample, whereas the central and western regions have bigger difference, reflecting the eastern region actor "leading role", to a certain extent, can reflect the overall and lead to the current development situation. From the interaction between different system variables, no matter in the eastern, central, western and national samples. There is a positive cyclic driving force between new energy industry agglomeration and regional economic green development, while there is a certain regional difference between other variables.

\subsubsection{Variance decomposition analysis}

Table 4.. Results of variance decomposition

\begin{tabular}{|c|c|c|c|c|c|c|c|c|c|c|c|c|c|}
\hline \multirow{3}{*}{$\begin{array}{c}\text { The response } \\
\text { variable }\end{array}$} & \multirow{3}{*}{ period } & \multicolumn{12}{|c|}{ Impact of variable } \\
\hline & & \multicolumn{3}{|c|}{ All the samples } & \multicolumn{3}{|c|}{ The east part } & \multicolumn{3}{|c|}{ The middle part } & \multicolumn{3}{|c|}{ The west part } \\
\hline & & $\begin{array}{c}\text { lnpergg } \\
\text { dp }\end{array}$ & lq & hci & $\begin{array}{c}\text { lnpergg } \\
\mathrm{dp}\end{array}$ & lq & hci & $\begin{array}{c}\text { lnpergg } \\
\mathrm{dp}\end{array}$ & lq & hci & $\begin{array}{c}\text { lnperg } \\
\text { gdp }\end{array}$ & lq & hci \\
\hline \multirow{6}{*}{ lnperggdp } & 1 & 1.000 & 0.000 & 0.000 & 1.000 & 0.000 & 0.000 & 1.000 & 0.000 & 0.000 & 1.000 & 0.000 & 0.000 \\
\hline & 2 & 0.999 & 0.001 & 0.000 & 0.920 & 0.079 & 0.001 & 0.794 & 0.160 & 0.046 & 0.979 & 0.010 & 0.011 \\
\hline & 3 & 0.989 & 0.008 & 0.003 & 0.841 & 0.156 & 0.003 & 0.680 & 0.263 & 0.057 & 0.955 & 0.035 & 0.010 \\
\hline & 5 & 0.964 & 0.022 & 0.014 & 0.692 & 0.306 & 0.002 & 0.679 & 0.264 & 0.057 & 0.939 & 0.044 & 0.017 \\
\hline & 8 & 0.923 & 0.061 & 0.016 & 0.596 & 0.403 & 0.001 & 0.605 & 0.320 & 0.075 & 0.927 & 0.054 & 0.018 \\
\hline & 10 & 0.908 & 0.076 & 0.015 & 0.574 & 0.425 & 0.001 & 0.580 & 0.339 & 0.081 & 0.926 & 0.056 & 0.019 \\
\hline \multirow{6}{*}{ lq } & 1 & 0.001 & 0.999 & 0.000 & 0.000 & 1.000 & 0.000 & 0.276 & 0.724 & 0.000 & 0.002 & 0.998 & 0.000 \\
\hline & 2 & 0.004 & 0.993 & 0.003 & 0.070 & 0.930 & 0.001 & 0.333 & 0.651 & 0.016 & 0.006 & 0.987 & 0.007 \\
\hline & 3 & 0.008 & 0.984 & 0.008 & 0.130 & 0.868 & 0.002 & 0.380 & 0.594 & 0.026 & 0.014 & 0.942 & 0.044 \\
\hline & 5 & 0.009 & 0.980 & 0.011 & 0.152 & 0.846 & 0.001 & 0.391 & 0.580 & 0.029 & 0.023 & 0.918 & 0.059 \\
\hline & 8 & 0.009 & 0.980 & 0.011 & 0.157 & 0.842 & 0.001 & 0.436 & 0.517 & 0.047 & 0.030 & 0.917 & 0.054 \\
\hline & 10 & 0.009 & 0.980 & 0.011 & 0.157 & 0.842 & 0.001 & 0.448 & 0.501 & 0.052 & 0.030 & 0.917 & 0.053 \\
\hline \multirow{6}{*}{ hci } & 1 & 0.002 & 0.052 & 0.947 & 0.070 & 0.011 & 0.919 & 0.180 & 0.016 & 0.803 & 0.000 & 0.051 & 0.949 \\
\hline & 2 & 0.017 & 0.221 & 0.762 & 0.093 & 0.132 & 0.775 & 0.350 & 0.027 & 0.623 & 0.000 & 0.052 & 0.948 \\
\hline & 3 & 0.031 & 0.339 & 0.631 & 0.095 & 0.153 & 0.752 & 0.439 & 0.036 & 0.525 & 0.005 & 0.052 & 0.943 \\
\hline & 5 & 0.040 & 0.418 & 0.542 & 0.099 & 0.199 & 0.702 & 0.447 & 0.196 & 0.357 & 0.026 & 0.056 & 0.919 \\
\hline & 8 & 0.039 & 0.430 & 0.531 & 0.099 & 0.204 & 0.697 & 0.468 & 0.251 & 0.282 & 0.029 & 0.057 & 0.914 \\
\hline & 10 & 0.038 & 0.431 & 0.530 & 0.100 & 0.204 & 0.696 & 0.458 & 0.287 & 0.255 & 0.029 & 0.057 & 0.913 \\
\hline
\end{tabular}


The variance is decomposed into components associated with each endogenous variable according to its cause, and the explanatory power of each shock to the change of endogenous variable of the system can be evaluated. Considering that the research period is too long and the time span is too large, more repeated information will appear and the variation gap between various systems will be covered, so the period number of variance decomposition is set as 1, 2, 3, 5, 8 and 10 .

From the national sample analysis, the contribution of the three endogenous variables is mainly from itself. The contribution of the other variables is gradually increasing with the growth of the time limit. The contribution of some variables is stagnant or even decreasing, but on the whole the contribution of different variables is still low. However, the contribution of the development of new energy industry to innovative human capital increased from $5.2 \%$ to $43.1 \%$, indicating that the impact of human capital on the development of new energy industry is gradually increasing. The contribution of the new energy industry to the economic green growth in the eastern region increased to $42.5 \%$ in the tenth period, indicating that the economic strength is an important driving force for the development of the new energy industry. The economic growth in the central region has increased from $27.6 \%$ to $44.8 \%$ in the initial development of the new energy industry, and its contribution to innovative human capital has increased from $18 \%$ to $45.8 \%$, which has become the main influencing factor. It indicates that the economic strength level of the central region is the primary influencing factor of each variable. The contribution of the three variables in the western region is more than $90 \%$, while the contribution of other variables is small.

\section{Conclusion and recommendations}

Based on the panel data of 30 provinces in China (except Xizang) from 2004 to 2016, this paper explores the regional coupling and coordinated development status and dynamic correlation among new energy industrial agglomeration, innovative human capital and green economic growth, and draws the following conclusions:

1. The agglomeration of new energy industry, innovative human capital and green economic development show the characteristics of "high coupling and low coordination". In recent years, the degree of coordinated development in most regions has increased, and the overall coordinated development shows a gradually decreasing distribution characteristic of "southeast coastal region, central inland region, northwest and southwest region".

2. From the dynamic correlation between variables, the agglomeration of new energy industry in China and the green development of regional economy have formed a good cyclic driving force, and innovative human capital has a potential long-term influence on the development of new energy industry.

3 . From the point of regional differences, the eastern region between the result of interaction with the sample size is consistent, "elites" is area, regional difference is mainly manifested in the Midwest, the central region economy has become an important support of human capital and the new energy industry, human resources has yet to translate into economic value and industry advantages. The accumulation of talents in western China lacks long-term and stable economic support, and the value of human resources is difficult to be realized in a short time.

Based on the above conclusions, the following policy recommendations are put forward:

First, build a collaborative innovation system of new energy industrial clusters and promote the industrialization development of intellectual achievements. Then form a two-wheel driving force for the green growth of regional economy. Strengthen the cooperative innovation system of the integration of production, education and research in the new energy industry, especially optimize the allocation of resources in the agglomeration area, and improve the innovation ability from all aspects. At the same time, attention should be paid to strengthening practical and innovative activities, relying on major science and technology projects, with related leading enterprises and research and development institutions as the main body, and vigorously promoting the cultivation of application-oriented talents.

Second, the training of new talents and the improvement of innovation system should be severely damaged, and the innovation value of human capital should be transformed into industrial achievements and economic value. More in their efforts to introduce the cultivation of high-level innovative talents and strengthen the goal-oriented mechanism reform talent development system, the human resources of corresponding innovation ability and the value of science and technology achievements, through policy guidance and market mechanisms to create conducive to speed up the transformation of innovative achievements of human capital for the economic value of macro environment, green development impetus for area.

Third, planning policies should be formulated according to local conditions based on regional differences. While giving full play to the "herd effect", the eastern region actively draws on advanced experience at home and abroad to further leverage the new energy industry and human resources to promote green economic growth. The central region should rely on the economic conditions, strengthen the policy support in the undertaking of industrial transfer and the implementation of talent introduction, and constantly improve the system and mechanism of the close combination of industrial development and talent resources. The western region should strengthen the long-term guarantee of human resources and promote the development of new energy industry by relying on abundant new energy resources.

\section{References}

[1] Shuang Qiu, Min Lin.Research on the Coupling and Harmonic Development of Iron and Steel Industry, 
Ecological Environment and Regional Economy: A Case Study of Panzhihua City [J]. Ecological Economy, 2021, 37 (02): 54-60+67. (in Chinese)

[2] Yuzhu Li, Boqun Tang. A study on the coupling and coordination relationship between economic development level and the supply of highly skilled talents: Based on panel data of 30 provinces in China from 2009 to 2018 [J]. China Vocational and Technical Education, 2021, (03): 82-90.(in Chinese)

[3] Di Zhou, Maoxiang Zhou. The coupling level difference and coupling path between human capital and economic growth in five urban agglomerations [J]. Statistics and Decision, 2020, 36 (20): 67-71. (in Chinese)

[4] Qintang Wu. Analysis on the coupling mechanism of industrial cluster and regional economic development [J]. Management World, 2004 (02): 133-134+136. (in Chinese)

[5] Xi Wang, Shuai He. The impact of structural tax reduction policy on consumer consumption: An analysis based on the PMAR model [J]. China Soft Science, 2016, (03): 141-150. (in Chinese)

[6] Ziye Li, Xianfeng Han, Genfu Feng. The impact of producer services agglomeration on the transformation of economic growth pattern in China: A heterogeneous threshold effect perspective [J]. Economic Management, 2015, 37 (12): 21-30. (in Chinese)

[7] Ling Lin, Shiping Yan, Haijian Zeng. Industrial agglomeration and human capital investment efficiency: Evidence from Chinese industrial enterprises [J]. Southern Economics, 2015, (02): 70-89. (in Chinese)

[8] Yunfei Zhang. An Empirical Study on the Relationship between Industrial Agglomeration and Economic Growth in Urban Agglomeration: Based on Panel Data Analysis [J]. Economic Geography, 2014, 34 (01): 108-113. (in Chinese)

[9] Xie Bo. Resource industry agglomeration, technological innovation ability and regional economic growth: an empirical analysis based on the provincial Panel [J]. Science and Technology Progress and Countermeasures, 2013, 30 (07): 31-36. (in Chinese)

[10] Huayou Zhu, Zejuan Dai, Ziran Jiang. Industrial agglomeration externalities, city size, and regional economic development: Empirical research based on dynamic panel data of 283 cities and GMM method [J]. Chinese Geographical Science, 2017, 27 (3).

[11] Loredana Pribac, Andrei Anghelina. Human Capital - The Effects of Education on Economic Growth Within the European Union [J]. Studia Universitatis "Vasile Goldis" Arad - Economics Series, 2015, 25 (3). 